\title{
Morphology of the Agriculture-based Deltaic Settlement in the Western Basin of the Chaophraya Delta
}

\author{
Jing Chen Yao Pan \\ Geological Research Center, Dalian University of Technology, Dalian, China
}

\begin{abstract}
The morphology of the horticulture based deltaic settlement in the Western Basin of Chaophraya Delta is clarified through an examination of the connection between the accompanying elements; geographical conditions and recorded and social foundation. This likewise mirrored the creation from land advancement, and the settlement development process. We isolated the example of settlement arrangement into 3 sorts; (1) Multi-driven organization settlement, (2) Strip-hub settlement, and (3) Singledriven settlement. These were then classified through thought of an examination interaction on the geological segment of the northsouth and west-east pivot of the Delta. Just as adjusting to the deltaic geological highlights, it very well may be viewed as that the examples and change interaction of these settlements were situated in resembled with; (1) inception of the Phrai framework, and (2) a declination of the Phrai framework. The Chinese merchants, who coordinated the waterfront market organization, could likewise be viewed as the key people who propelled this cycle. It very well may be viewed as that the multi-driven organization settlement was created under the influence of the Phrai framework, while the fish-bone sort strip-pivot settlement was created later a declination of the Phrai framework.
\end{abstract}

Keywords: Chaophraya Delta; Western Young Delta; Deltaic settlement; Phrai system

Citation: Jing Chen, Yao Pan, 2018. Morphology of the Agriculture-based Deltaic Settlement in the Western Basin of the Chaophraya Delta. Journal of Sustainable Urbanization, Planning and Progress, 3(1): 26-31. http://doi.org/10.26789/JSUPP.2018.01.004

Copyright: Morphology of the Agriculture-based Deltaic Settlement in the Western Basin of the Chaophraya Delta. (C) 2018 Jing Chen, Yao Pan. This is an Open Access article published by Urban Development Scientific Publishing Company. It is distributed under the terms of the Creative Commons Attribution-Noncommercial 4.0 International License, permitting all non-commercial use, distribution, and reproduction in any medium, provided the original work is properly cited and acknowledged.

\section{Introduction}

The Chaophraya Delta is viewed as one of the main water assets in the South East Asian area; alongside the Mekong, Irrawaddy and Red deltas. Its waste limit covers a space of $12,000 \mathrm{Km} 2$, which is half of the entire focal plain region including the Bangkok Metropolis Area (BMA), and is around 2\% of the entire country. Over $25 \%$ of the whole populace is presently living in this focal plain region. It is without a doubt obvious that the Chaophraya Delta is the spine, which gives a rich living climate to the Thai public. Be that as it may, trailing the extreme changes in the Delta by the quick advancement with no sufficient plan, considering of the deltaic geographical conditions, this made a ton of effects a living climate from a home unit scale to local scale. This review has a point on; (1) Clarifying the change cycle of land recovery and land advancement in the Western Lower Basin of the Delta, and (2) Clarifying the arrangement interaction and highlights of horticulture based deltaic settlement connected with above condition. This was in the works by investigation of; (1) the connection between land geology, land use and settlement design in a review region removed from overlaying the different topographical layers blended from planning through; geological guides of the Delta done by Supajanya T., Wanasilp P. what's more Takaya Y.; 1/250,000 geological guides of territories in the Delta region studied, during 1987-1996, by the Royal Thai Survey Department; and 1/50,000 topographical guides of areas in the Western Lower Basin region overviewed, during 1910-1913, by the Royal Thai Survey Department, (2) the connection of above information in corresponding with agribusiness creation interaction, social and chronicled foundation of the Delta, from the Ayuddhaya time frame to the Rattanakosin time frame, in view of writing audits; meetings and field review in the Western Basin of the Delta, including the Amphwa area, the Bangkoknoi stream organization and Bangkok old city region; directing a few times from 1996-1998 and 2000-2004. 


\section{Background}

\subsection{Topographical Features}

The Delta had been gradually transformed, at least two times since the last ice age and since 2-3 thousand years ago, from a seabed area of Gulf of Thailand to a lowland swamp area with the height 1-3 meters from over sea level. For this reason, this Delta could be separated in to two parts of the Old Delta and the Young Delta. While the Old Delta is a plain drainage area of water from the northern mountainous region and has 5-30 meters high over sea level, the Young Delta is a lower wetland area of 1-3 meters high over sea level. *Contact Author: Mr.Terdsak Tachakitkachorn, Lecturer, Faculty of Architecture, Chulalongkorn University, Thailand Tel: +66-2226-3048 e-mail: terdsak@gmail.com (Received May 10, 2005 ; accepted August 31, 2005) 362 JAABE vol.4 no. 2 November 2005 Terdsak Tachakitkachorn. Due to its different topographical conditions, the geographical features of the central part of Thailand can be divided into four parts as follows: (a) Mountainous and jungle area, (b) Plain area, (c) Lowland area and (d) Coastline area. The Delta, which is formed by four main basins; the Maeglong, Tahchin, Chaophraya and Bangpalong basins, is mostly occupied by (b), (c) and (d) areas. While the (c) area in the western part of the Chaophraya Delta, including the Maeglong and Tahchin basins, is densely covered by orchards and wetlands respectively, the (c) area in the eastern part is covered by rice fields, as seen in the whole plain area. Moreover, the (d) area in the western part of the Chaophraya Delta was occupied by salt fields or waste lands, with mangrove at their estuaries and branches. Generally, it is well known that the water system in the lowland area of the Delta is influenced greatly by the influence from (1) the fl ow of fresh-water from the upper watershed area and (2) the sea tide from the Southern coastline area. Before land reclamation, the lowland area was a swamp occupied by nipa-palm with a mangrove jungle along the natural levee, and a dunelike terrain in the back marsh area. In the dry season, the land would turn into a vast muddy terrace, but in the rainy season, it would be submerged by overflow from the upper stream and high sea tide, which would last for half a year. At least a thousand years ago, the Deltaic conditions in the lowland area, were not only unsuitable for settlement, but also unsatisfactory for agriculture. However, following land reclamation and development for agriculture-based settlement, this wetland area was transformed into a wide area of neighborhoods, consisting of orchards and paddy fi elds through the newly excavated waterway network.

\subsection{Historical and Social Background}

The settlement formation process, in parallel with historical and social background, has been classified into 4 periods as follow;

(1) Pre-Rattnakosin Period ( - 1782) From the evidence of the land development for orchards, along the Maeglong and Chaophraya rivers, it is clear that orchardneighborhoods had already formed in the Young Delta since the Ayuddhaya period. With migration of the royal family from Ayuddhaya $i$ and enforcement of the "Phrai system ii", these aristocrats would have brought with them the commoners, who would be the main source of labor in reclaiming the marsh jungle area as orchards. Moreover, they would make use of their connection with Ayuddhaya City, and dominate the trading between the Old and the Young Delta iii. After the development of orchard settlements in the centric trading area of the Young Delta, this would also create a connection between other former settlements in the coastline area, including the neighborhoods in the mangrove and marsh areas, and along the estuary of small creeks along the coastline. JAABE vol.4 no.2 November 2005 Terdsak Tachakitkachorn 363

(2) Rattanakosin early Period (1782-1851) After the establishment of the Rattanakosin dynasty at the Bangkok Neighborhood along the Chaophraya River by King Rama the first, the connection between the Bangkok and Amphwa Neighborhoods became more intimate iv. At the same time as the Rattanakosin City became the center of the Kingdom of Siam, the Amphwa Neighborhood was also promoted to the neighborhood of new established royal family, and became a significant center of the Western Basin. The key persons, who motivated the connection between these two neighborhoods and the development of these centric neighborhoods into the town neighborhoods, were overseas Chinese v. These people also contributed much in the development of the waterfront markets and the product distribution network in the Western Basin. We could also identify some settlements in the coastline area that had backgrounds related to these overseas Chinese vi.

(3) Rattanakosin middle Period (1851-1961) After declination of the "Phrai system" during the reign of King Rama the fourth and the fifth era, commoners were freed from their masters. This happened at the same time that the Kingdom of Siam was forced to dissolve the former economy dominated by the Royal family, after the Bowring Treaty vii. This led to the great dissolution of centric-community based on the masters under the "Phrai system". Thus, there would be some commoners 
who left their conventional masters and migrated to an undeveloped area of the Young Delta. This could also be considered the great distribution of man-labor to the whole of the Young Delta. These people participated in the land development project, including the excavation of irrigation waterways connecting the basins.

\section{Settlement Formation Process}

\subsection{Criteria}

There are two processes to be considered, correlatively, for an explanation of the settlement formation in the Delta: (1) process under west-east sectional axis of the Delta, and (2) process under northsouth sectional axis of the Delta.

(1) West-East axis

Considered in parallel with the deltaic geographical features, we could divide the subject land into 2 parts as, (1) Natural levee or land along the main waterway of each basin, and (2) Back marsh or land behind or in-between Basins or those main waterways. This could be described in correlation with the ease of water circulation. The first one or natural levee area, with its higher and stable foundation, would have more ability in terms of water circulation than the second one, or the back marsh area.

(2) North-South axis

Considering in parallel with the geographical features of the river from the Old delta to the Young Delta, we could divide the subject land into 3 parts as; (A) Upper area (of the Lower Young Delta) or plain (1) Zone-A: Considered from its topographical conditions, the entire Zone-A was different from Zone-B and Zone-C, with its more inclined slope and ability in water drainage. Thus, both Zone-A.1 and Zone-A. 2 were more suitable for rice fields without any raised-bed system. In Zone-A.1 with its stable natural levee, people could plant the home-orchards without use of the raised-bed system. However, after the excavation of Khlong Damnernsaduak, the lower part of Zone-A.2 was developed into modern raised-bed areas for whole year cultivation of orchards and vegetable fields, by Chinese people and free commoners. area, (B) Central area (of the Lower Young Delta) or lowland area, and (C) Lower area or coastline area.

This could be described from the water mechanism system. The Upper area (A), which has a steeper slope than the others, would receive more influence from fresh water, while the Lower area (C) would receive more influence from seawater. And as the middle part of the whole Lower Young Delta, the Central area (B) would receive influence from both waters. We could classify the land features of the Western Basin into 6 zones as; (A.1)
Plain area + Natural levee, (A.2) Plain area + Back marsh, (B.1) Lowland area + Natural levee, (B.2) Lowland area + Back marsh, (C.1) Coastline area + Natural levee, and (C.2) Coastline area + Back marsh. And, we could describe the details, zone by zone, as follows; 364 JAABE vol.4 no. 2 November 2005 Terdsak Tachakitkachorn (2) Zone-B: There is no exact evidence regarding the original land feature of this zone. However, considering the geographical features in the Tahchin Basin, Zone-B.1 in both the Maeglong and Chaophraya rivers, would be occupied mostly by Nipa-palm jungle. After introduction of the traditional raised-bed orchard system into the Delta, at least five hundred years ago, the most obvious land development for orchard settlement would be conducted in the Maeglong and Chaophraya lower basins, and this would be started from Zone-B.1. On the other hand, Zone-B.2 between both the Maeglong-Tahchin and Tahchin-Chaophraya rivers would be occupied by weed fields and a scattering of rugged muddy-mold terrain. After expansion of the supplementary waterway network from Khlong Damnernsaduak, Zone-B.2 would have been turned into a mix of rice fields and traditional raised-bed orchard areas. This was gradually turned into the modern raisedbed orchards and vegetable fields. (3) Zone-C viii: In Zone-C.1 of the Chaophraya and Tahchin Basins, we could see that those areas along coastline and estuary were occupied by mangrove jungle, with Nipa-palm jungle in the deeper creeks. This typical landscape would also be seen in the Maeglong River before the development. However, compared to the narrower strip of mangrove jungle in the Tahchin Basin, mangrove jungle in the whole Zone-C of the Chaophraya and Meglong Basins was spread in broader bands. We could not see the same kind of broadband features of the mangrove jungle in the Zone-C. 2 between the Maeglong-Tahchin Rivers, and half of the Zone-C. 2 between the Tahchin-Chaophraya Rivers.

Zone-C.2 between the Maeglong-Tahchin Rivers was occupied by vast vacant muddy terrain mixed with a scattering of mangrove terraces, while half of Zone-C.2 between the Tahchin- Chaophraya Rivers was occupied by vacant muddy terrain with mangrove strips along the inner-area creeks. Khlong Sunakhorn and Khlong Darn, shortcut waterways excavated during the Ayuddhaya period, could be considered as the separating line of Zone-C and Zone-B between the Maeglong-Tahchin Rivers and the Tahchin-Chaphraya Rivers respectively. With this specific topographical feature, it is clear that most of the settlements in Zone-C could not be developed into agricultural land, but were primarily based on fishery, shell farms, salt fields, and mangroves. 


\subsection{Pattern of Settlement Formation}

From the above explanation of the settlement formation process based on both social and topographical background, we could explain the pattern of the settlement formation in the Western Basin of the Delta as follows;

(1) Multi-centric network Settlement: Orchard areas of the Amphwa and Bangkok Neighborhoods occupied most of the area in Zone-B.1, and expanded into Zone-B.2. We could identify the distribution of settlements formed closely together in the whole waterway network of orchard neighborhoods. From their historical background, the settlements in this area were developed mainly by the commoners of aristocrats from Ayuddhaya City. With a demand for fruit products for Ayuddhaya City, as the main motivating factor, this mangrove jungle area would have been developed by the commoners. JAABE vol.4 no.2 November 2005 Terdsak Tachakitkachorn 365, from the distribution pattern of the temples, the land development for orchard settlement was conducted based on each centric point along the waterways, one by one, separately. After completion of the waterway network through expansion of the orchard areas, these centric points of each settlement were connected and formed the big grouping of the multi-centric network of orchard neighborhoods. The main centric point of each settlement in this whole orchard neighborhood was eventually developed into the waterfront market or town.

(2) Strip-axis Settlement: (Single-linear type, Fishbone type) This Strip-axis settlement could be mostly seen along the short-cut waterways, including the short-cut waterway between basins or as a dividing line of each Zone, and the short-cut waterways into back marsh areas in Zone-B.2. Unlike the multi-centric network settlement, which formed a network pattern with highdensity expansion to the back marsh area; this stripaxis settlement formed the dwelling units and temples along the main waterway, without expansion into its back marsh area. The settlement formation would start in an obvious linear direction, with a single-axis, and would then gradually split its branches into the back marsh area. Thus, it would be developed into the pattern of fi sh-bone type settlement, as seen in the Khlong Damnernsaduak and Khlong Paseecharern. These newly excavated irrigation waterways functioned as a backbone axis for the dwelling-units, which lay along them closely together, with considerable branch waterways separated at regular intervals. Despite the expansion of land development to the back marsh area by these latter branch waterways, most of the dwelling units were still gathered along the main waterway. Thus, dwelling units in the newly developed orchards in the back marsh area had comparatively low density. It was different from the orchard settlement in the Amphwa and Bangkok Neighborhoods that this network settlement was formed as an extension of the linear features, not the unification of network by various centric settlements. It can be seen from its social background that this kind of land development was conducted individually by independent families, unlike the settlements in the Amphwa and Bangkok Neighborhoods, which developed under the supervision of masters with their intensive man-labors. On the other hand, we could see the single-linear type settlement in case of settlements along Khlong Sunakhorn and Khlong Daarn. These two Khlong were the dividing line between Zone-B and Zone-C. They were comparatively much older than the upper Khlong Damnernsaduak and Khlong Paseecharern. Unlike the fi sh366 JAABE vol.4 no. 2 November 2005 Terdsak Tachakitkachorn JAABE vol.4 no. 2 November 2005 Terdsak Tachakitkachorn 367 bone type settlement, there were fewer branch waterways in these two main waterways. The settlements along these main waterways were isolated from each other, with their independent temples at the center. This can be explained by the severe topographical conditions of the coastline area and that few people could form their settlement in an area without enough fresh water. In addition, these settlements were not in the area of agricultural production, but in the area of mangrove and salt production.

(3) Single-centric Settlement: Strip-shape, Egg-shape, Pin-shape This Single-centric settlement could be mostly seen in the mangrove area or back marsh area in Zone-C. They made a living not by agricultural production, but from fishing, shell farming, charcoal production, or salt production. The fishing settlements could be separated into two types as; (1) fishing settlement located at the estuary of a river, and (2) fishing settlement located at the estuary of small waterways or creeks along the coastline. The first one had their settlement features in a big connecting Stripshape. But, it was different from the Strip-axis settlement in that the dwellingunits were comparatively more compact, with their spatial structure formed in a vertical line rather than in a horizontal direction to the waterway. At the same time, it was different from the multi-centric settlement in that it had few temples as the settlement center. The second one was a small group of dwellings that were isolated and both distant and independent from each other. They were settled at the mouth of waterways, which were channeled to salt fields in the back marsh area. Thus, with the settlement as a head and waterway as a tail, we call this a Pin-shape settlement. The last one was the singlecentric settlement in the big group pattern. This kind of 
settlement would have been the old settlement, the same as those of the old orchard neighborhoods, including the Yeesarn and Sakhla Neighborhoods. At the beginning, these would have been fishing settlements. However, the first one was later developed into a charcoal-producing neighborhood, while the second one was developed into a salt producing neighborhood. Compared to the other single-centric settlements in Zone-C, these were formed into comparatively bigger grouping patterns. Moreover, they were located at the center of the mangrove territory for charcoal production, and the territory of the saltfields for salt production. Thus, we call this grouping of dwelling-units in the middle of the production area, the Egg-shape settlement.

\section{Conclusions}

We classified the pattern of settlements in the Western Young Delta into three types as follows: (1) Multicentric network Settlement: This type of settlement was developed from a mangrove and marsh area into an orchard area by the aristocrats with their man-labor from Ayuddhaya. Each group of settlements developed a temple as its own center. Finally, these groups were connected to each other by waterways and formed a comparatively high density of orchard neighborhoods. In addition, based on the influence of the aristocrats and Chinese traders, this was developed to the center of product and distribution. (2) Strip-axis Settlement (Single-linear type, Fish-bone type): This type of settlement was developed as a new orchard neighborhood, in parallel with the migration of free commoners from other surrounding areas, after declination of the Phrai system. In the same way as the multi-centric network settlement, this was also developed into the new center of product distribution. (3) Single-centric Settlement (Strip-shape, Egg-shape, Pinshape): This type of settlement was developed before or in the same period as those multi-centric network orchard settlements. Early settlements in the mangrove or salt-field production areas had their specific character as separated individual settlements. We summarized the transformation process of agriculture-based deltaic settlements in the Western Basin of the Chaophraya Delta as follows: 1) Land development for the first agriculturebased deltaic settlement along the main river, during the enforcement of the Sakdina system: The natural levees of the main rivers and waterways can be considered the most suitable areas for the first period development. This area would have been selected due to its location advantage in that it provided a freshwater supply in-land and a seaaccessible coastline. There were already some settlements formed in this undeveloped area, however, they were not agriculturebased settlements, but mainly fishing settlements. After land development, which initiated the raised-bed orchard system and rice fields in the central area of the Young Delta, agriculture-based settlements were formed along the main rivers, with the later excavating irrigation waterways. Settlement development was carried out using the intensive man-labor of the commoners. Accordingly, this could be developed into a multi-centric network settlement, and with the influence of the aristocrats and overseas Chinese, was developed into a center for product distribution in the Western Young Delta. 2) Land development of undeveloped area for the later agriculture-based deltaic settlement, after declination of the Sakdina system: Together with the increasing demand for agricultural products, there was a need to develop more agriculture land. This was solved by the great migration of humanlabor for the reclamation of undeveloped back marsh areas in the Young Delta, during declination of the Phrai system. The development projects were carried out by the excavation of irrigation waterways between each Basin, including Khlong Damnernsaduak and Khlong Paseecharern. Different from the first developed agriculture-based deltaic settlements, the latter ones along these new irrigation waterways were formed in a comparatively scattered pattern, due to their individual social structure. 368 JAABE vol.4 no.2 November 2005 Terdsak Tachakitkachorn Among these settlements in the Western Young Delta, the multi-centric network settlement could be considered the one that was developed not only by following the topographical features of the Delta, but also based on a specific social background. It had a great effect on the development of this orchard settlement from an undeveloped area to a center of waterfront markets and product distribution. It is also clear that the emergence of this multi-centric network settlement enhanced the settlement development process in the entire Western Young Delta, through the development of a waterway network for product distribution.

\section{References}

[1] Jantanee L. (1991) A study of community pattern and land use of the lower Maeglong flood plain (Master thesis). Chulalongkorn University.

[2] Kasetsart University (2000) Proceeding of the International Conference; The Chao Phraya Delta: Historical Development, Dynamics and Challenges of Thailand's Rice Bowl.

[3] Ksetisiri C. (2003) Discovering Ayutthaya. Toyota foundation.

[4] Lertpanichkul S. (2000) YuuYaangPhrai (As commoners). Narnmee Book. 
[5] Supajanya T. and Wanasilp P. (1980) Report on a study of historic cities along the old coastline of the Central part of Thailand. Chulalongkorn University.

[6] Tachakitkachorn T. (2003) The waterfront market network and Product distribution system in Amphwa Neighborhood (The study of Sustainable Agriculture-based Society in Maeglong Lower basin1), Journal of Architecture and Planning (Transaction of AIJ), pp.91-99 2003.2.

[7] Takaya Y. (1971) Physiography of rice land in the Chaophraya Basin of Thailand. Southeast Asia Research Institute.
[8] Tessiri O. (1981) Land holding in Thailand from 1901-1932: A case study of Monthon Krungthep (Master Thesis). Chulalongkorn University.

[9] Thep S. (1997) Pongsawadarn Rajshanigul Bangchang (Story of Bangchang royal family).

[10] Thai History Review Committee. (1991) KamHaiGarn KhunLuang WatPradusongtam (Testimony of KhunLuangWatPradusongtam). Offi ce of the Prime Minister).

[11] Yantrasast K. (1995) Bangkok's Water Logic: A study on the Phenomenon of Water and Urban Transformation (Doctor Thesis). The University of Tokyo. 